\title{
Laryngeal mask for airway management in open tracheal surgery-a retrospective analysis of 54 cases
}

\author{
Martina Krecmerova $^{1}$, Jan Schutzner ${ }^{2}$, Pavel Michalek ${ }^{3,4}$, Paul Johnson ${ }^{4}$, Tomas Vymazal ${ }^{1}$ \\ ${ }^{1}$ Department of Anaesthesiology and Intensive Care Medicine, 2nd School of Medicine, ${ }^{2}$ Department of Surgery, 1st School of Medicine, Charles \\ University, University Hospital, Motol, Prague, Czech Republic; ${ }^{3}$ Department of Anaesthesiology and Intensive Care, 1st Faculty of Medicine, \\ Charles University and General University Hospital, Prague, Czech Republic; ${ }^{4}$ Department of Anaesthesia, Antrim Area Hospital, Antrim, UK \\ Contributions: (I) Conception and design: M Krecmerova, P Michalek, T Vymazal; (II) Administrative support: All authors; (III) Provision of study \\ material or patients: M Krecmerova, J Schutzner, P Michalek, T Vymazal; (IV) Collection and assembly of data: M Krecmerova, J Schutzner, P \\ Michalek, T Vymazal; (V) Data analysis and interpretation: M Krecmerova, P Michalek, P Johnson, T Vymazal; (VI) Manuscript writting: All \\ authors; (VII) Final approval of manuscript: All authors. \\ Correspondence to: Tomas Vymazal. Department of Anaesthesiology and Intensive Care, 2nd School of Medicine, Charles University, University \\ Hospital Motol, V Úvalu 84, 15006 Prague 5, Czech Republic. Email: tomas.vymazal@fnmotol.cz.
}

\begin{abstract}
Background: Airway management in tracheal resections presents many challenges. The aim of this retrospective analysis is to report the efficacy and complications associated with the use of the laryngeal mask airway in this procedure.

Methods: The charts of 54 consecutive patients operated for tracheal stenosis during the period 2009-2016 were reviewed. This cohort included only resections of the trachea. We evaluated total success rate of laryngeal mask insertion (\%), insertion success rate on the first attempt, the quality of intraoperative ventilation through the laryngeal mask, the quality of fibre optic view through the device, incidence of bleeding during the first $24 \mathrm{~h}$, signs of dehiscence of the anastomosis within $48 \mathrm{~h}$ and 30-day mortality.

Results: The laryngeal mask airway provided a patent airway throughout the procedure in 52 (96.4\%) patients. Insertion of the device failed in $1(1.8 \%)$ patient due to abnormal upper airway anatomy. Another patient $(1.8 \%)$ developed laryngeal mask malposition during intraoperative neck extension subsequently requiring tracheal intubation. Fibre optic view through the devices including insertion of the flexible bronchoscope was satisfactory in $52(96.4 \%)$ patients. Serious complications, such as pulmonary aspiration, early postoperative bleeding or suture dehiscence were not observed in this cohort.

Conclusions: Based on this analysis of 54 patients, we would consider the laryngeal mask airway a feasible alternative to the tracheal tube for airway management and ventilation during open tracheal surgery.
\end{abstract}

Keywords: Tracheal stenosis resection; laryngeal mask airway; total intravenous anesthesia (TIVA)

Submitted Aug 11, 2017. Accepted for publication Mar 29, 2018.

doi: $10.21037 /$ jtd.2018.04.73

View this article at: http://dx.doi.org/10.21037/jtd.2018.04.73

\section{Introduction}

Open resection of the stenotic part of the trachea is complex thoracic procedure performed only in specialized centers. Surgical resection is the most effective treatment for short stenosis of the trachea and its carina. With careful patient selection, meticulous surgical and anesthetic techniques, both perioperative mortality and complication rates are considered acceptable (1). Adequate access to the lumen of trachea is required by the surgeon; simultaneously sufficient ventilation and gas exchange must be provided by the anesthesiologist $(2,3)$. Adequate ventilation and oxygenation should be provided both in the pre-operative stenotic airway and in the intra/post-operative transected airway. Management of a patent airway in the immediate postoperative period is also challenging due to tracheal 


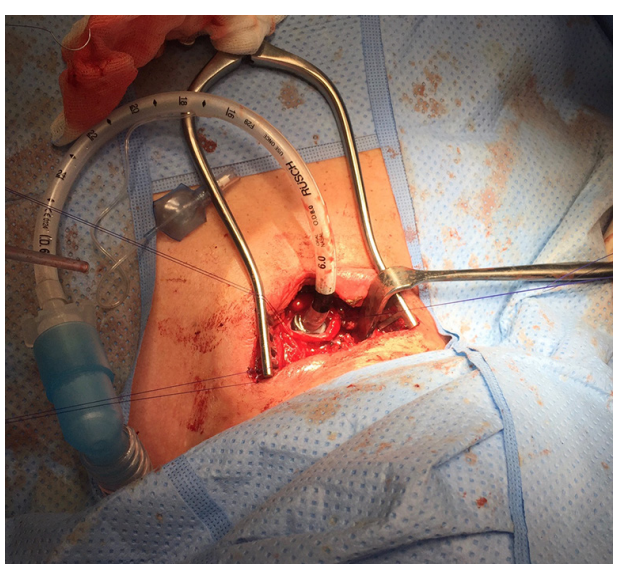

Figure 1 Armoured endotracheal tube inserted into the distal stump of trachea during surgical resection.

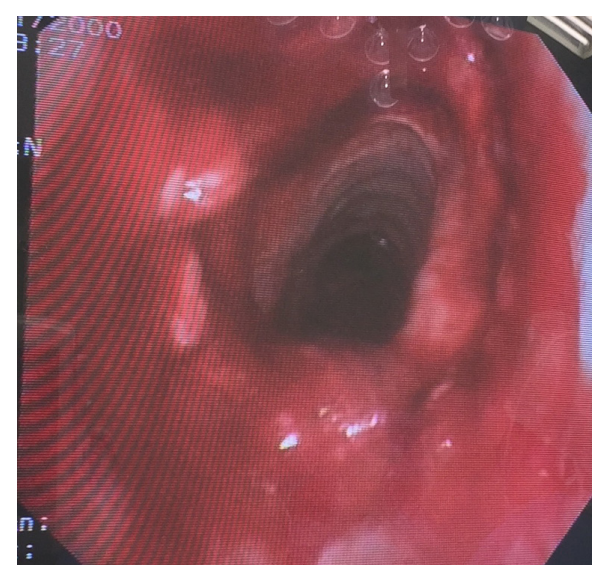

Figure 2 Fiber optic view through the LMA for assessment of the tracheal suture. LMA, laryngeal mask airway.

edema and forced cervical flexion positioning (4). Any cough or gagging should be strictly avoided because it can cause rupture of tracheal anastomosis (5).

Tracheal intubation with a narrow tracheal tube is the historic method of choice for airway management in this procedure $(2,3)$. However, case reports describing other methods of airway management, including supralaryngeal jet ventilation (6) or use of supraglottic airway devices (7) have been published. The aim of this retrospective study was to describe our experience with airway management using the laryngeal mask airway in open tracheal surgery.

\section{Methods}

We retrospectively analyzed airway management strategy in 54 consecutive patients who underwent open surgery for tracheal stenosis in our university hospital during 2009-2016 period. This cohort included only resections of the trachea, no carinal reconstructions or tumor resections were performed during the study period. Anesthesia and perioperative care were provided only by experienced cardiothoracic anesthesiologists. The Ethics Committee of the Teaching Hospital Motol approved (EK-3/16) retrospective data collection and analysis. All enrolled patients signed the written informed consent. Data collection was performed by two researchers (M Krecmerova, T Vymazal) using anesthetic charts, surgical protocols and computerized data from hospital information system.

General anesthesia was performed in a standardised manner following the hospital protocol for open tracheal surgery procedures. Boluses of propofol, remifentanil and rocuronium were used for induction of anesthesia while maintenance was provided using total intravenous anesthesia (TIVA) with continuous infusion of these three agents. Single-use laryngeal masks LarySeal ${ }^{\mathrm{TM}}$ (Flexicare Medical Ltd, Cynon Halley Business Park, Mountain Ash Mid Glemorgag CF45 4ER, UK) were inserted after induction to anesthesia in all patients. A nasogastric tube was inserted in order to confirm the course of the esophagus and trachea. Special connectors allowing insertion of the flexible bronchoscope were attached to the laryngeal mask after securing the airway. The patients were ventilated with volume controlled ventilation (VCV), using tidal volumes of $6 \mathrm{~mL} / \mathrm{kg}$, positive end-expiratory pressure (PEEP) of $4 \mathrm{cmH}_{2} \mathrm{O}$ and allowing peak inspiratory pressures up to a maximum of $20 \mathrm{cmH}_{2} \mathrm{O}$. Electrocardiography, pulse oximetry, non-invasive or invasive blood pressure and capnography (end-tidal concentration of $\mathrm{CO}_{2}$ ) were monitored in all patients during the course of surgery.

The trachea was transected below the stenosis during an apnoeic pause. An armoured endotracheal tube was then inserted to the distal stump of the trachea allowing controlled ventilation of both main bronchi during this stage of procedure (Figure 1). In the meanwhile, the laryngeal mask airway (LMA) was kept in situ. The surgeons subsequently resected the stenotic part of trachea and performed "end-to-end" anastomosis. At the terminal stage of the anastomosis, the endotracheal tube was removed and apnoea was allowed. Once the anterior section of the anastomosis was completed, then the dorsal cervical neck extension was changed to cervical flexion in order to minimize tension of the created suture. At this point, 
Table 1 Demographic data

\begin{tabular}{lcccc}
\hline $\begin{array}{l}\text { Demographic } \\
\text { data }\end{array}$ & $\mathrm{n}$ & $(\%)$ & Mean/median & SD/IQR \\
\hline Total number & 54 & 100 & - & - \\
Males & 35 & 65 & - & - \\
Females & 19 & 35 & - & - \\
Age (years) & - & - & 51.5 & 15.1 \\
BMl (kg/m $\left.{ }^{2}\right)$ & - & - & 29.2 & 5.9 \\
Mallampati & - & - & 2 & $1-2$ \\
score & & & 4 & $3-4$ \\
LMA size & - & - & 4 & \\
\hline
\end{tabular}

$\mathrm{SD}$, standard deviation; BMI, body mass index; IQR, interquartile range; LMA, laryngeal mask airway.

Table 2 Origin and characteristics of tracheal stenosis

\begin{tabular}{lcccc}
\hline Parameter & Number & $\%$ & Mean SD \\
\hline Origin of stenosis & 54 & 100 & & \\
Post-tracheostomy & 39 & 72 & & \\
Surgical tracheostomy & 35 & 65 & & \\
Dilational tracheostomy & 4 & 7 & & \\
Post intubation & 15 & 28 & & \\
Distance from the vocal cords to & & & 3.5 & 0.57 \\
stenosis (cm) & & & & \\
2 & 2 & 3.7 & & \\
3 & 2 & 3.7 & & \\
4 & 6 & 11 & & \\
5 & 7 & 13 & & \\
6 & 14 & 26 & & \\
7 & 13 & 24 & & \\
8 & 7 & 13 & & \\
9 & 3 & 5.5 & & \\
Length of stenosis (mm) & & & 8.64 \\
\hline
\end{tabular}

ventilation was initiated via the laryngeal mask airway. During emergence, residual neuromuscular blockade was reversed using sugammadex under cautious "train-offour" monitoring in all patients. Fibre optic visualisation of the suture was performed in all patients using a flexible bronchoscope (Figure 2). At the end of the surgery the LMA was removed in all patients when fully awake and spontaneously breathing. They were subsequently transferred to the surgical intensive care unit (ICU) for postoperative care.

Apart from demographic data, the following parameters were evaluated: total success rate of laryngeal mask insertion (\%), insertion success rate on the first attempt, the quality of intraoperative ventilation through the laryngeal mask, the quality of fibre optic view through the device, incidence of bleeding during the first $24 \mathrm{~h}$, signs of dehiscence of the anastomosis within $48 \mathrm{~h}$ and 30-day mortality. The data was expressed as mean and standard deviation (SD).

\section{Results}

In total, 54 patients undergoing open tracheal surgery were analyzed. Demographic data is expressed in Table 1, while characteristics of the stenosis are analyzed in Table 2. The laryngeal mask airway was used in all of them. LMA was successfully inserted in $53(98.1 \%)$ patients (Table 3). Forty-nine $(90.7 \%)$ devices were inserted on the first attempt. All these LMAs were introduced with satisfactory fibre optic view and enabled adequate oxygenation and ventilation with no periods of hypoxemia or hypercarbia during the surgery. Peak airway pressures were maintained up to $20 \mathrm{cmH}_{2} \mathrm{O}$ in all patients. We observed audible leak during controlled ventilation in $1(1.9 \%)$ patient associated with a drop in $\mathrm{SpO}_{2}$ to $91 \%$ from $94 \%$ at the beginning of surgery. The procedure was initiated with the LMA but due to neck extension the device was dislocated in the course of surgery. Successfully re-insertion of the LMA was not feasible due to anatomical changes caused by radiotherapy and prior surgical resections in the upper airway because of the laryngeal cancer. The patient was subsequently intubated with a standard single-lumen cuffed endotracheal tube. Controlled ventilation through the LMA was not possible in another patient, due to chronic stiff oedema of the laryngeal inlet. This patient therefore had to be subsequently intubated by a standard single-lumen cuffed endotracheal tube prior to surgery and then underwent the procedure. We did not observe any episode of bleeding and/or dehiscence of the "end-to-end" anastomosis within $48 \mathrm{~h}$ after surgery in the 52 patients who were successfully managed with the LMA. The 30-day mortality rate was zero. The outcome measures are summarized in Table 3.

\section{Discussion}

Results of this retrospective analysis suggest that the 
Table 3 Intraoperative parameters, main outcomes and complications

\begin{tabular}{|c|c|c|c|c|}
\hline Intraoperative parameters & Mean & SD & Incidence & $\%$ \\
\hline Duration of anesthesia (min) & 103.1 & 7 & & \\
\hline Duration of surgery (min) & 128.2 & 14 & & \\
\hline $\begin{array}{l}\text { GA induction to LMA } \\
\text { insertion (sec) }\end{array}$ & 113.2 & 7.8 & & \\
\hline $\begin{array}{l}\text { LMA intracuff pressure } \\
\left(\mathrm{cmH}_{2} \mathrm{O}\right)\end{array}$ & $\geq 60$ & & & \\
\hline $\begin{array}{l}\text { Successful insertion and } \\
\text { ventilation with LMA }\end{array}$ & & & 52 & 96.3 \\
\hline $\begin{array}{l}\text { Satisfactory fibre optic view } \\
\text { through the LMA }\end{array}$ & & & 52 & 96.3 \\
\hline $\begin{array}{l}\text { Adequate end-tidal carbon } \\
\text { dioxide during } \mathrm{CMV}\end{array}$ & & & 52 & 96.3 \\
\hline $\begin{array}{l}\text { End-tidal carbon dioxide } \\
\text { tension during CMV }\end{array}$ & 5.6 & 0.47 & & \\
\hline Adequate $\mathrm{paO}_{2}$ and $\mathrm{spO}_{2}$ & & & 52 & 96.3 \\
\hline Intraoperative $\mathrm{spO}_{2}(\%)$ & 94.6 & 1.4 & & \\
\hline LMA insertion failure & & & 1 & 1.9 \\
\hline $\begin{array}{l}\text { Intraoperative leak during } \\
\mathrm{CMV}\end{array}$ & & & 1 & 1.9 \\
\hline Pulmonary aspiration & & & 0 & 0 \\
\hline Bleeding at $24 \mathrm{~h}$ & & & 0 & 0 \\
\hline Suture dehiscence at $48 \mathrm{~h}$ & & & 0 & 0 \\
\hline Mortality at 30 days & & & 0 & 0 \\
\hline
\end{tabular}

SD, standard deviation; GA, general anesthesia; LMA, laryngeal mask airway; CMV, controlled mandatory ventilation.

laryngeal mask airway may be a safe and effective alternative to tracheal intubation in open tracheal surgery.

The most commonly reported airway management technique in tracheal surgery is standard orotracheal intubation using an armoured endotracheal tube (3). After opening the trachea below the stenosis, another sterile endotracheal tube is inserted into the distal segment by the surgeon (8). Supraglottic devices such as laryngeal mask airways or i-gel are preferred by some authors in connection with high-frequency jet ventilation in endoscopic management of tracheal lesions and endobronchial procedures $(9,10)$. Use of the supraglottic airway devices in open tracheal surgery has been reported only in two isolated case reports. Both authors employed high-frequency jet ventilation during the procedure $(7,11)$.
A nasogastric tube could be inserted prior to the induction of general anesthesia to confirm the course of the esophagus and trachea. Cardiopulmonary bypass (CPB) (12) or extracorporeal membrane oxygenation (ECMO) (13) has been used as a life-saving method in patients with ultimate tracheal stenosis and severe dyspnoe.

In our centre, we have used LMAs in tracheal surgery for several years. Unlike tracheal intubation, a laryngeal mask airway does not irritate the tracheal mucosa and still allows fibre optic visualisation of the anastomosis. The risk of excessive cough during emergence should be significantly reduced with the LMA use, thus protecting the anastomosis against dehiscence. We found the LMA also safe and effective with regard to oxygenation and ventilation apart from one case of impaired ventilation due to LMA dislocation during neck flexion. The LMA is also an effective airway device during intraoperative manipulation of the patient. The advantage of bronchoscopic access via the LMA is facilitated by a usually higher internal diameter as compared with an endotracheal tube (ET). The relative wide bore of the LMA or other supraglottic device also allows insertion of a wide diameter flexible bronchoscope with more effective suctioning of blood or secretions from the trachea. However, supraglottic airway devices may be associated with serious complications such as pulmonary aspiration (14). Also the relationship between excessive LMA intracuff pressures and postoperative pharyngolaryngeal morbidity is becoming increasingly documented. We maintained the intracuff pressure within limits suggested by the manufacturer and did not observe any difficulties during the surgery. The use of laryngeal masks is associated with better hemodynamic stability at induction and emergence (15). This may be beneficial mainly in patients with significant cardiac pathology. Another advantage of conventional volume-controlled ventilation with peak pressures up to $20 \mathrm{cmH}_{2} \mathrm{O}$ may be in the reduction of blood spraying when compared with high or low frequency ventilation.

Most centers advocate TIVA as a preferred method of anesthesia $(2,8)$. General anesthesia prevents patient movements during the procedure, protects them against stressful experience from the surgery itself and it is also comfortable for the surgeons. Several case reports described awake tracheal resection with spontaneous ventilation under a regional anesthesia technique such as cervical epidural or bilateral cervical plexus block $(16,17)$. Some authors consider the tubeless tracheal surgery feasible and safe in case of tracheal resection and 
reconstruction for management of benign stenosis (18). The limitations of LMAs seem to be anatomical changes following radiotherapy, stiff tissue oedema of the upper airway and critical tracheal stenosis. Contraindications for the use of supraglottic airway devices involve increased risk for aspiration, morbid obesity, intraoral pathology an any potentially bleeding conditions (19). More advanced supraglottic airway devices may be more advantageous in this indication because of higher seal pressure, wide breathing lumen and presence of an additional channel for insertion of the gastric tube and we are currently moving towards the use of these devices during open tracheal surgery.

\section{Conclusions}

Based on our experience the laryngeal mask airway seems to be effective alternative to tracheal intubation in open resections of the trachea.

\section{Acknowledgements}

None.

\section{Footnote}

Conflicts of Interest: The authors have no conflicts of interest to declare.

Ethical Statement: The Ethics Committee of the Teaching Hospital Motol approved (EK-3/16) retrospective data collection and analysis. Written informed consent was obtained from all patients for publication of this manuscript and any accompanying images. A copy of the written consent is available for review by the Editor of the journal.

\section{References}

1. Liu XY, Liu FY, Wang Z, et al. Management and surgical resection for tumors of the trachea and carina: experience with 32 patients. World J Surg 2009;33:2593-8.

2. Roman PE, Battafarano RJ, Grigore AM. Anesthesia for tracheal reconstruction and transplantation. Curr Opin Anaesthesiol 2013;26:1-5.

3. Hatipoglu Z, Turktan M, Avci A. The anesthesia of trachea and bronchus surgery. J Thorac Dis 2016;8:3442-51.

4. Auchincloss HG, Wright CD. Complications after tracheal resection and reconstruction: prevention and treatment. J
Thorac Dis 2016;8:S160-7.

5. Bibas BJ, Terra RM, Oliveira Junior, et al. Predictors of postoperative complications after tracheal resection. Ann Thorac Surg 2014;98:277-82.

6. Rezaie-Majd A, Bigenzahn W, Denk DM. Superimposed high-frequency jet ventilation (SHFJV) for endoscopic laryngotracheal surgery in more than 1500 patients. $\mathrm{Br} \mathrm{J}$ Anaesth 2006;96:650-9.

7. Adelsmayr E, Keller C, Erd G, et al. The laryngeal mask and high-frequency jet ventilation for resection of high tracheal stenosis. Anesth Analg 1998;86:907-8.

8. Zhao W, Li CH, Jia NG, et al. Analysis of anesthetic methods for tracheal resection and reconstruction with artificial trachea: a report of 25 cases. Zhonghua Wai Ke Za Zhi 2008;46:981-4.

9. Vorasubin N, Vira D, Jamal N, et al. Airway management and endoscopic treatment of subglottic and trachea stenosis: the laryngeal mask airway technique. Ann Otol Rhinol Laryngol 2014;123:293-8.

10. Arevalo-Ludena J, Arcas-Bellas JJ, Alvarez-Rementeria $\mathrm{R}$, et al. A comparison of the i-gel supraglottic device with endotracheal intubation for bronchoscopic lung volume reduction coil treatment. J Clin Anesth 2016;31:137-41.

11. Biro P, Hegi TR, Weder W, et al. Laryngeal mask airway and high-frequency jet ventilation for the resection of a high-grade upper tracheal stenosis. J Clin Anesth 2001;13:141-3.

12. Chiu CL, Teh BT, Wang CY. Temporary cardiopulmonary bypass and isolated lung ventilation for tracheal stenosis and reconstruction. Br J Anaesth 2003;91:742-4.

13. Keeyapaj W, Alfirevic A. Carinal resection using an airway exchange catheter-assisted venovenous ECMO technique. Can J Anaesth 2012;59:1075-6.

14. Michalek P, Donaldson W, Vobrubova E, et al. Complications associated with the use of supraglottic airway devices in perioperative medicine. BioMed Res Int 2015;2015:746560.

15. Bennett SR, Grace D, Griffin SC. Cardiovascular changes with the laryngeal mask airway in cardiac anaesthesia. $\mathrm{Br} \mathrm{J}$ Anaesth 2004;92:885-7.

16. Liu J, Li S, Shen J, et al. Non-intubated resection and reconstruction of trachea for the treatment of a mass in the upper trachea. J Thorac Dis 2016;8:594-9.

17. Macchiarini P, Rovira I, Ferrarello S. Awake upper airway surgery. Ann Thorac Surg 2010;89:387-90.

18. Caronia FP, Loizzi D, Nicolosi T, et al. Tubeless tracheal resection and reconstruction for management of benign 
stenosis. Head Neck 2017;39:E114-7.

19. Hernandez MR, Klock PA Jr, Ovassapian A. Evolution of the extraglottic airway: a review of its history,

Cite this article as: Krecmerova M, Schutzner J, Michalek P, Johnson P, Vymazal T. Laryngeal mask for airway management in open tracheal surgery - a retrospective analysis of 54 cases. J Thorac Dis 2018;10(5):2567-2572. doi: 10.21037/jtd.2018.04.73 applications, and practical tips for success. Anesth Analg 2012;114:349-68. 